\title{
Effects of Deposition Time on the Chemical Bath- deposited CuS Thin Films
}

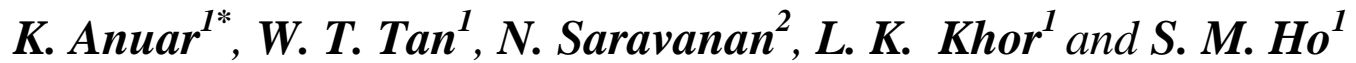 \\ ${ }^{1}$ Department of Chemistry, Faculty of Science, Univ. Putra Malaysia, 43400 Serdang, Malaysia \\ ${ }^{2}$ Department of Bioscience and Chemistry, Faculty of Engineering and Science, Univ. Tunku Abdul \\ Rahman, 53300 Kuala Lumpur, Malaysia. \\ e-mail:anuar@science.upm.edu.my
}

\begin{abstract}
The chemical bath deposition technique was used to deposit thin films of copper sulphide onto indium tin oxide glass substrates. The bath composition included copper chloride which was the source of $\mathrm{Cu}^{2+}$ and sodium thiosulfate which supplied the $\mathrm{S}^{2-}$ ions. $\mathrm{X}$ ray diffraction and atomic force microscopy were used to investigate structural and morphological characterization, respectively. The influence of deposition time was studied to determine the optimum condition for deposition process. The deposited CuS films showed hexagonal structure. The number of peaks attributable to $\mathrm{CuS}$ increased as the deposition time was increased to 16 hours based on XRD data. AFM images revealed that the chemical bath-deposited films for 16 hours showed more homogeneous and uniform compared with other deposition times, and the highest absorbance value was obtained for the films deposited at this period. The band gap energy decreased from 2.9 to $2.45 \mathrm{eV}$ when the deposition time was increased from 8 to 20 hours.
\end{abstract}

Keywords: Chemical bath deposition, copper sulphide, thin films, solar cells.

\section{Introduction}

Nowadays, thin film semiconductors have attracted ever increasing attention due to their potential in many industries. Among them, copper sulfide is the most commonly used material. The copper sulfide thin film attracts attention of many researchers mostly due to its semiconducting properties. In addition, the constituent elements of this material $(\mathrm{Cu}$ and $\mathrm{S})$ are non-toxic and abundant in nature. The copper sulfide film can play a significant role in solar cells, solar control coatings, microwave shielding coatings, electroconductive electrodes and photothermal conversion applications and so on. Many techniques such as chemical bath deposition ${ }^{1}$, SILAR $^{2}$, spray pyrolysis ${ }^{3}$, electrodeposition ${ }^{4}$ and photochemical deposition $^{5}$ have been developed to synthesize copper sulfide thin film.

${ }^{*}$ Corresponding author 
Chemical bath deposition technique is one of the simple and low cost methods which can operates at low processing temperature and also gives large deposition area. The method requires a source of chalcogen ions and metal ions to deposit on the substrates. The preparations of various thin films like $\mathrm{SnS}^{6}, \mathrm{ZnS}^{7}, \mathrm{CdS}^{8}, \mathrm{CuInS}_{2}{ }^{9}, \mathrm{Zn}_{\mathrm{x}} \mathrm{Cd}_{1-\mathrm{x}} \mathrm{S}^{10}$ and $\mathrm{Cu}_{4} \mathrm{SnS}_{4}{ }^{11}$ have been reported by several authors using chemical bath deposition method.

In the present work, influence of the deposition time on the $\mathrm{CuS}$ film was investigated from acidic solutions at room temperature. The results of the investigations on structural, morphological and optical properties of $\mathrm{CuS}$ thin films have been carried out by using X-ray diffraction, atomic force microscopy and UV-Vis spectrophotometer techniques, respectively.

\section{Experimental Methods}

All the chemicals used for the deposition were analytical grade and all the solutions were prepared in deionized water (Alpha-Q Millipore). The copper sulfide thin film was prepared from an acidic bath using aqueous solutions of copper chloride $\left(\mathrm{CuCl}_{2} \cdot 2 \mathrm{H}_{2} \mathrm{O}\right)$ and sodium thiosulfate $\left(\mathrm{Na}_{2} \mathrm{~S}_{2} \mathrm{O}_{3} .5 \mathrm{H}_{2} \mathrm{O}\right)$ acted as a source of $\mathrm{Cu}^{2+}$ and $\mathrm{S}^{2-}$ ions, respectively. The indium tin oxide (ITO) glass was used as the substrate for the chemical bath deposition of the CuS thin film. Before chemical bath deposition, the glass was degreased with ethanol for 10 minutes, and then ultrasonically cleaned with distilled water for $10 \mathrm{~min}$ and dried in desiccators. The $\mathrm{CuS}$ thin film deposit was carried out at room temperature by using following procedure: $25 \mathrm{~mL}$ of $\mathrm{CuCl}_{2}(0.05 \mathrm{M})$ was taken in a $100 \mathrm{~mL}$ beaker and $25 \mathrm{~mL}$ of $\mathrm{Na}_{2} \mathrm{~S}_{2} \mathrm{O}_{3}(0.05 \mathrm{M})$ was mixed in it with constant stirring. The $\mathrm{pH}$ of resultant solution was adjusted to 3 by adding drop wise hydrochloric acid. The cleaned ITO glass substrate was immersed vertically into beaker. The deposition process was carried out at different deposition times of $8,12,16$ and $20 \mathrm{~h}$ in order to determine the optimum condition for the deposition of $\mathrm{CuS}$ thin film. After the deposition, the films were washed with distilled water and kept for analysis.

The structure of the film was monitored using X-ray diffraction (XRD) with a Philips PM 11730 diffractometer equipped with a $\operatorname{CuK}_{\alpha}(\lambda=0.15418 \mathrm{~nm})$ radiation source. The surface morphology, thickness and roughness were examined by recording atomic force microscopy images with a Q-Scope 250 in contact mode with a commercial $\mathrm{Si}_{3} \mathrm{~N}_{4}$ cantilever. Value of root mean square (RMS) roughness was calculated from the height values in the atomic force microscopic images using the commercial software. The optical properties of the chemical bath-deposited films were measured with a Perkin Elmer UV/Vis Lambda 20 Spectrophotometer in the wavelength range of 300 to $800 \mathrm{~nm}$. The film-coated indium tin oxide glass was placed across the sample radiation pathway while the uncoated indium tin oxide glass was put across the reference path. From the analyses of absorption spectra, the band gap energy $\left(\mathrm{E}_{\mathrm{g}}\right)$ of the $\mathrm{CuS}$ film was determined. 


\section{Results and Discussion}

Figure 1 shows the XRD patterns of the $\mathrm{CuS}$ thin film deposited at different deposition times. The sample prepared at shorter time (Figure 1a) shows only single peak at $2 \theta=29.3^{\circ}$ corresponding to d-spacing value of $3.04 \AA$. However, as the deposition time was increased to 12 and 16 hours, the number of peaks attributed to $\mathrm{CuS}$ increased to four and seven peaks, respectively. Identification of the peaks on the XRD patterns shows the films are polycrystalline in nature and the crystal structure was identified to be hexagonal. The lattice parameter values are $\mathrm{a}=\mathrm{b}=3.768 \AA, \mathrm{c}=16.27 \AA, \alpha=90^{\circ}, \beta=90^{\circ}, \gamma=120^{\circ}$. The corresponding d-spacing values are well in agreement with the Joint Committee on Powder Diffraction Standard data (JCPDS reference code: 00-065-3928) belonging to the $\mathrm{CuS}^{12}$ compound. Beyond this point, any increase in the deposition time resulted in the reduction in the number of $\mathrm{CuS}$ peaks. The disappearance of five peaks of $\mathrm{CuS}$ that correspond to (102), (105), (106), (110) and (202) planes could be observed. On the other hand, no copper peaks, sulphur peaks or unassigned peaks are observed indicating that the CuS films obtained is pure without existence of any impurity. However, the appearance of two other peaks attributable to indium tin oxide (JCPDS reference No.: 01-089-4597) ${ }^{13}$ at $2 \theta=30.5^{\circ}$ and $50.8^{\circ}$ with interplanar distances of 2.91 and $1.79 \AA$, respectively, could be detected. The presence of indium tin oxide peaks comes from the substrates during deposition process.

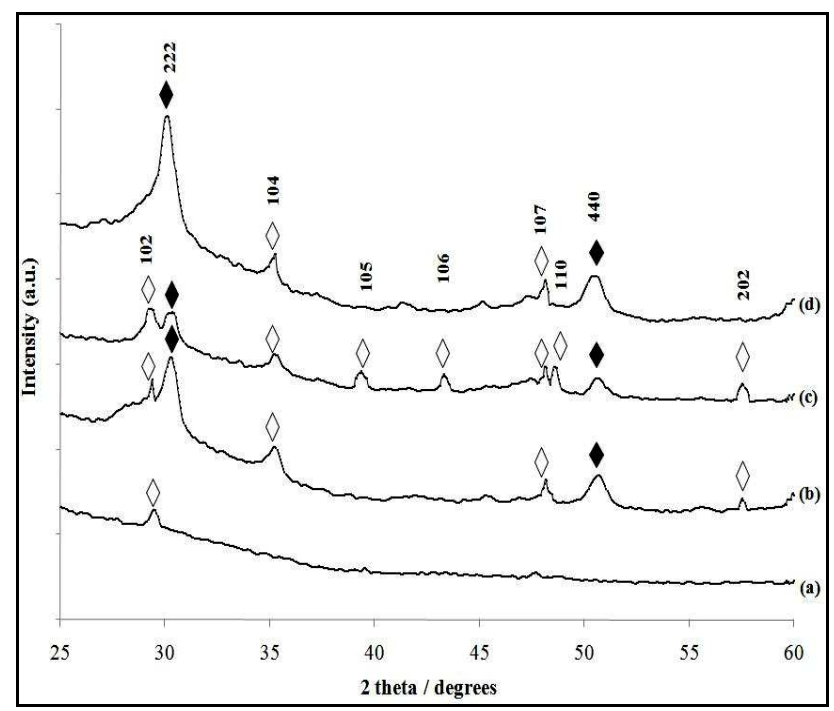

Figure 1: $X$-ray diffraction patterns of $\mathrm{CuS}$ thin film deposited at different deposition times (a) $8 h(b) 12 h(b) 16 h(d) 20 h\left(\diamond C u S, \diamond \operatorname{In}_{1.875} \mathrm{O}_{3} \mathrm{Sn}_{0.125}\right)$.

The surface morphology of the copper sulfide thin film deposited on ITO glass substrates has been investigated by atomic force microscopy (AFM). Figure 2 shows twodimensional AFM images $(5 \mu \mathrm{m} \times 5 \mu \mathrm{m})$ of the surface film deposited at various deposition times. The AFM results suggested that the influence of deposition time on the surface morphology is significant. At shorter time $(8$ and $12 \mathrm{~h})$, the grains were found to be fine and the films showed incomplete coverage of material over the surface of substrate. The film 
prepared at $16 \mathrm{~h}$ reveals smooth surface with larger grain size and high degree of homogeneity as compared with the films deposited at shorter periods. The grain sizes were almost similar to each other. The thin films deposition process on an indium tin oxide substrate depends mainly on the formation of nucleation sites and subsequent growth of the $\mathrm{CuS}$ film from this centre. For the film deposited for $20 \mathrm{~h}$, the grain formation was observed as irregular grain sizes different from one another. The spherical grains were merged in each other. These observations suggest an incomplete nucleation step with irregular growth rate of the grains.

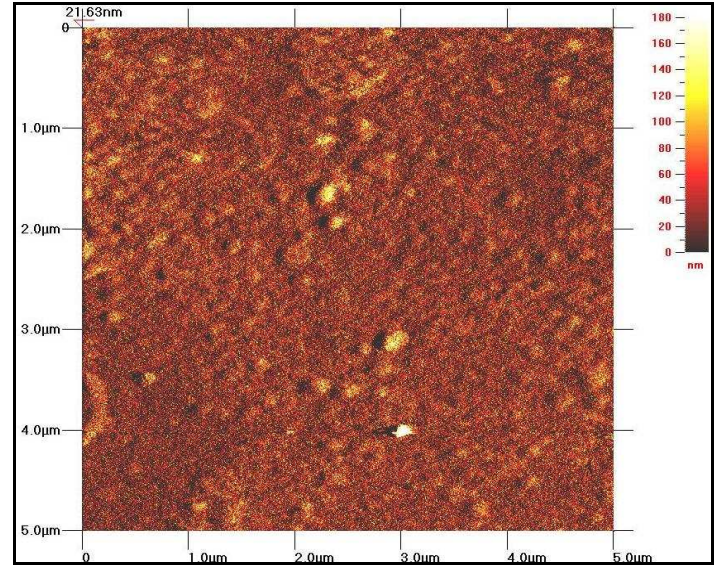

(a)

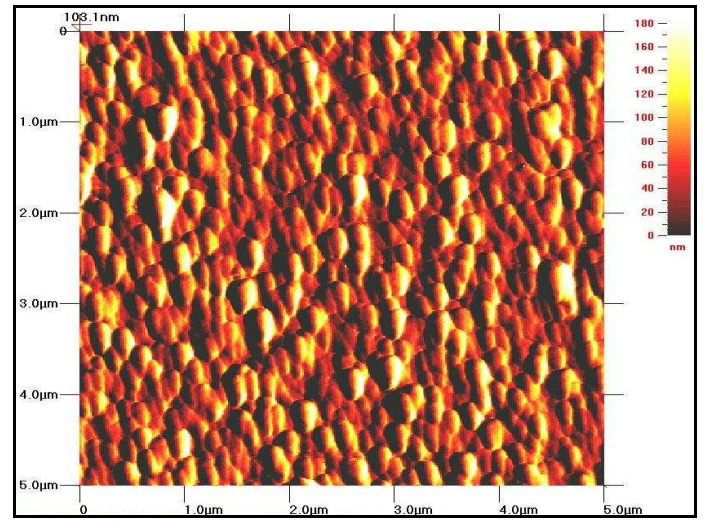

(c)

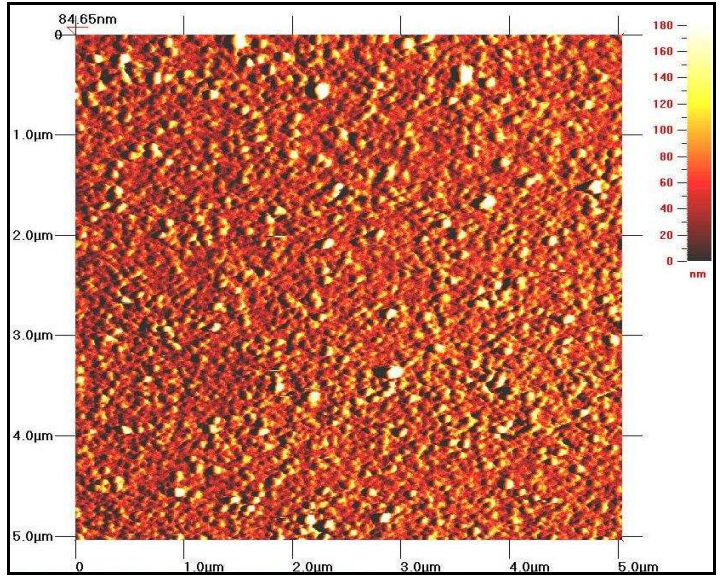

(b)

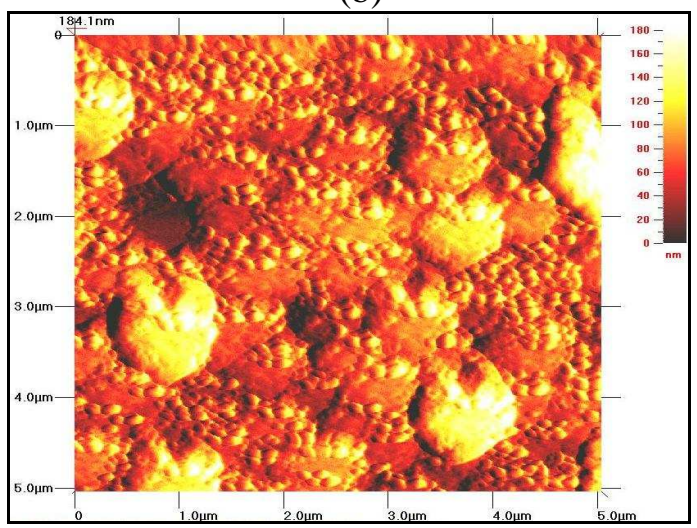

(d)

Figure 2: Atomic force microscopic images of $\mathrm{CuS}$ thin film deposited at different deposition times; (a) $8 h(b) 12 h(b) 16 h(d) 20 h$.

The investigation on the surface roughness and the thickness of thin films from 2-D AFM images was carried out by many researchers ${ }^{14-16}$. Root mean square (RMS) roughness is defined as the standard deviation of the surface height profile from the average height, is the most commonly reported measurement of surface roughness ${ }^{17}$. The roughness values of 4, 5, 7 and $25 \mathrm{~nm}$ were estimated for samples prepared for 8, 12, 16 and $20 \mathrm{~h}$, respectively. 
The thickness of the films was studied using AFM images. At the right side of the images (Fig. 2), an intensity strip is shown, which indicates the depth and height along the $z$ axis. The thickness values of 22, 85, 103 and $184 \mathrm{~nm}$ have been observed for samples deposited for $8,12,16$ and $20 \mathrm{~h}$, respectively. This result indicates that an increase in deposition time allows more materials to be deposited onto indium tin oxide substrate and thicker $\mathrm{CuS}$ film to be formed. We can conclude that the increase in the size of the grains leads to an increase in the thickness and roughness of the films.

Figure 3 shows copper sulfide thin films deposited onto ITO glass substrate under different deposition times. The absorbance of film deposited for $16 \mathrm{~h}$ produced the highest absorbance value compared with other deposition times due to more $\mathrm{CuS}$ materials, which were formed under this condition. This result is also supported by the number of $\mathrm{CuS}$ peaks shown in the XRD patterns in Fig.1.

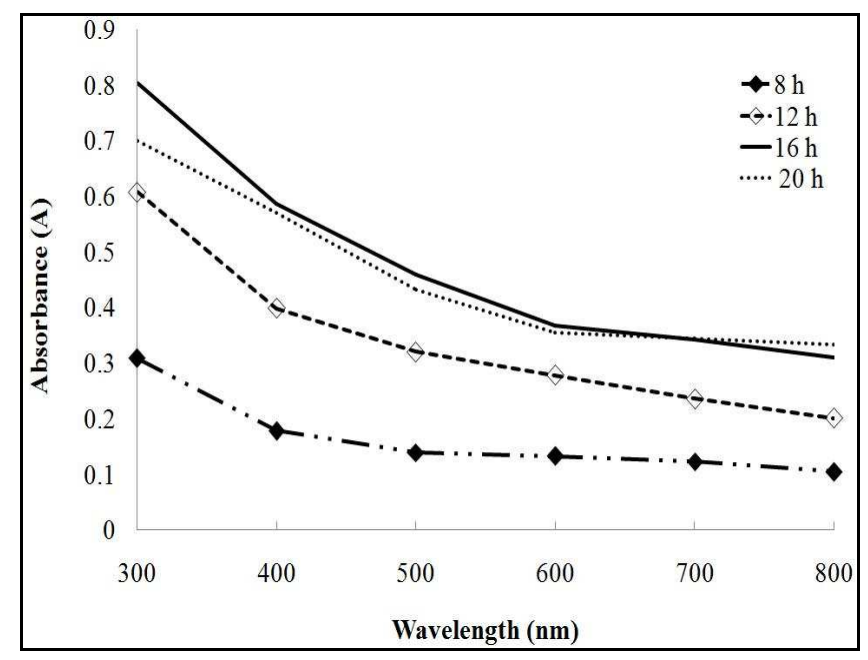

Figure 3: Absorbance versus wavelength spectra of CuS thin film deposited at various deposition times.

In order to determine the band gap of thin films, the equation of Stern ${ }^{18}$ was used.

$$
\mathrm{A}=\frac{\left[\mathrm{k}\left(\mathrm{hv}-\mathrm{E}_{\mathrm{g}}\right)^{\mathrm{n} / 2}\right]}{\mathrm{hv}}
$$

where, $v$ is the frequency, $h$ is the Planck's constant, $k$ equals a constant while $n$ carries the value of either 1 or 4 . The $n$ value is 1 for a direct gap material and 4 for indirect gap material. The plot of $(A h v)^{2}$ against $h v$ for the films deposited at various deposition times is presented in Fig. 4. For a direct band gap semiconductor $(n=1)$, the $(A h v)^{2}$ against $h v$ is predicted to be a straight line with a photon energy $(h v)$ axis intercept giving the band gap value ${ }^{19}$. The band gap energies of the thin film of CuS deposited for $8,12,16$ and $20 \mathrm{~h}$ were $2.9,2.8,2.6$ and $2.45 \mathrm{eV}$, respectively. The band gap energy decreased with increasing the grain size of the film. It has been reported that the direct band gap energy of the copper sulfide thin film using SILAR method was $2.36 \mathrm{eV}^{20}$. 


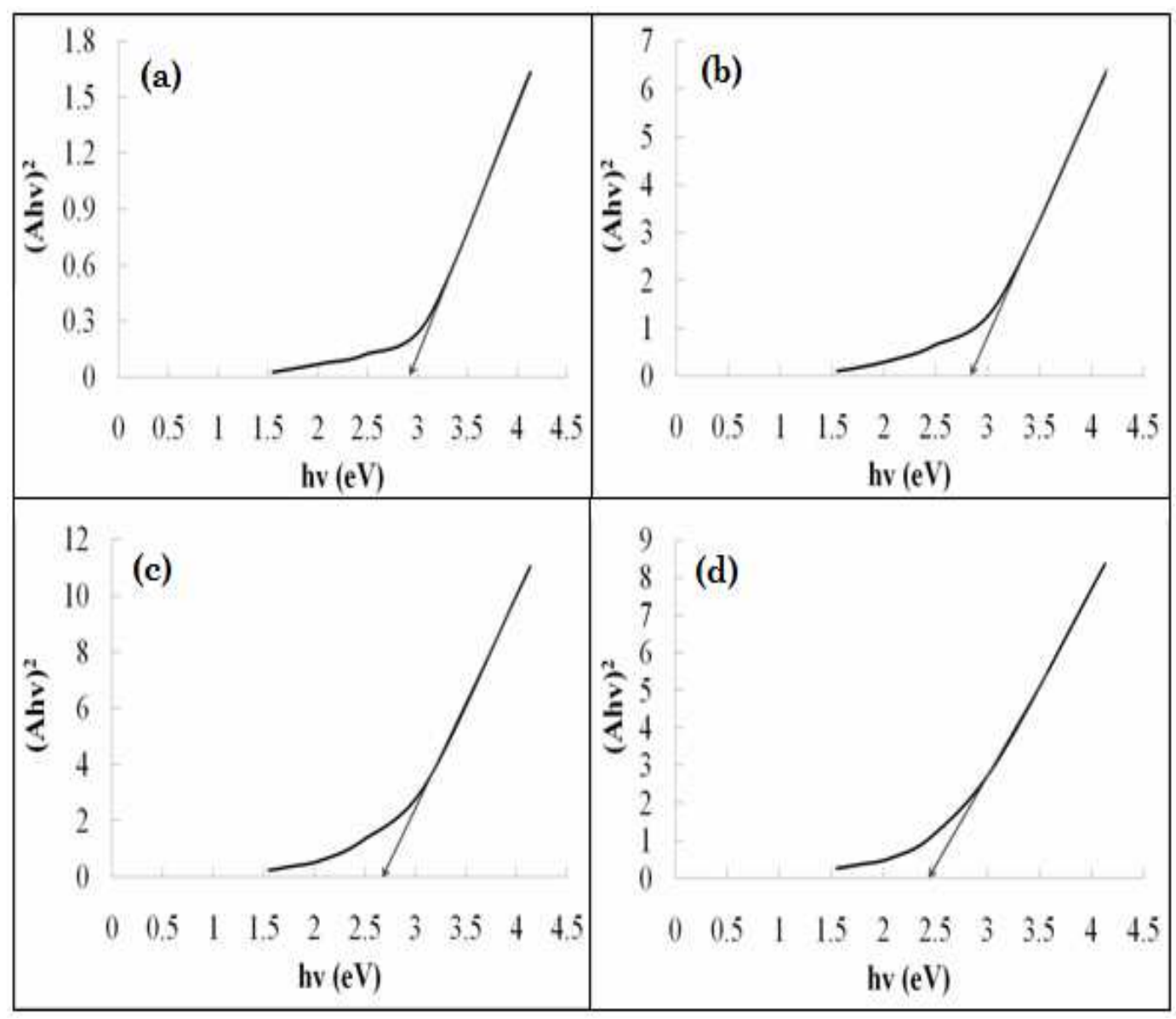

Figure 4: Plot of $(A h v)^{2}$ versus hv of CuS thin films deposited at various deposition times. (a) $8 h(b) 12 h(b) 16 h(d) 20 h$.

\section{Conclusions}

The thin $\mathrm{CuS}$ film was deposited on indium tin oxide glass substrate using simple chemical bath deposition technique. From the X-ray diffraction analysis, it is found that the deposited thin $\mathrm{CuS}$ film is of hexagonal phase. The film deposited at $16 \mathrm{~h}$ showed the best optimum condition for the preparation of the thin $\mathrm{CuS}$ film because of good crystallinity, uniform surface coverage and higher absorption characteristics when compared to the films prepared at other deposition times. These results matched well with the information obtained from the X-ray diffraction, atomic force microscopy and optical properties. 


\section{Acknowledgements}

The authors would like to thank the Department of Chemistry, University of Putra Malaysia for the provision of laboratory facilities and Ministry of Science, Technology and Innovation (MOSTI) for the National Science Fellowship.

\section{References}

1. M. T. S. Nair and P. K. Nair, Semicond. Sci. Technol., 1989, 4, 191.

2. F. W. Zhuge, X. M. Li, X. D. Gao, X. Y. Gan and F. L. Zhou, Mater. Lett., 2009, 63, 652 .

3. C. Nascu, I. Pop, V. Ionescu, E. Indrea and I. Bratu, Mater. Lett., 1997, 32, 73.

4. K. Anuar, Z. Zainal, M. Z. Hussein, N. Saravanan and I. Haslina, Sol. Energy Mater. Sol. Cells, 2002, 73, 351.

5. J. Podder, R. Kobayashi and M. Ichimura, Thin Solid Films, 2005, 472, 71.

6. P. P. Hankare, A. V. Jadhav, P. A. Chate, K. C. Rathod, P. A. Chavan and S. A. Ingole, J. Alloys Compd., 2008, 463, 581.

7. R. Sahraei, G. M. Aval, A. Baghizadeh, M. Lamehi-Rachti, A. Goudarzi and M. H. M. Ara, Mater. Lett., 2008, 62, 4345.

8. N. S. Kozhevnikova, A. A. Rempel, F. Hergert and A. Magerl, Thin Solid Films, 2009, 517, 2586.

9. F. Cui, L. Wang, Z. Xi, Y. Sun and D. Yang, J. Mater. Sci.-Mater. Electron, 2009, 20, 609.

10. W. C. Song and J. H. Lee, J. Korean Phys. Soc., 2009, 54, 1660.

11. K. Anuar, W. T. Tan, M. S. Atan, K. A. Dzulkefly, H. Md. Jelas, S. M. Ho and N. Saravanan, J. Ultra Chem., 2009, 5, 21.

12. Y. Takeuchi, Y. Kudoh and G. Sato, Z. Kristallogr., 1985, 173, 119.

13. N. Nadaud, N. Lequeux, M. Nanot, J. Jove and T. Roisnel, J. Solid State Chem., 1998, 135, 140.

14. F. Iacomi, M. Purica, E. Budianu, P. Prepelita and D. Macovei, Thin Solid Films, 2007, 515, 6080.

15. W. Y. Li, X. Cai, Q. L. Chen and Z. B. Zhou, Mater. Lett., 2005, 59, 1.

16. M. Kwoka, L. Ottaviano and J. Szuber, Thin Solid Films, 2007, 515, 8328.

17. T. Jiang, N. Hall, A. Ho. and S. Morin, Thin Solid Films, 2005, 417, 76.

18. F. Stern, Solid State Phys., 1963, 15, 299.

19. M. Krunks, O. Bijakina, T. Varema, V. Mikli and E. Mellikov, Thin Solid Films, 1999, 338, 125.

20. S. D. Sartale and C. D. Lokhande, Mater. Chem. Phys., 2000, 65, 63. 